\title{
Optimization of the crystallinity of polypropylene/submicronic-talc composites: The role of filler ratio and cooling rate
}

\author{
A. Makhlouf ${ }^{1}$, H. Satha ${ }^{1}$, D. Frihi ${ }^{1}$, S. Gherib ${ }^{1}$, R. Seguela ${ }^{2}$ \\ ${ }^{1}$ Laboratoire des Silicates, Polymères et Nanocomposites, Université 8 Mai 1945, BP 401, 24000 Guelma, Algérie \\ ${ }^{2}$ MATEIS, INSA de Lyon - CNRS UMR5510, Campus LyonTech La Doua, 69621 Villeurbanne, France
}

Received 31 July 2015; accepted in revised form 12 October 2015

\begin{abstract}
Micronic and submicronic mineral fillers recently appeared as efficient reinforcing agents for polyolefins in addition to the benefit of bypassing the exfoliation/dispersion problem encountered in the case of incorporation of nanoscopic fillers such as clay. Submicronic-talc, designated as $\mu$-talc, belongs to this kind of new fillers. This work was aimed at searching to optimize the crystallinity ratio of isotactic polypropylene in the presence of $\mu$-talc in relation to the filler ratio of the composites and the cooling rate from the melt. In order to highlight the efficiency of the $\mu$-talc on the crystallization of polypropylene comparison has been made with PP composites containing conventional talc particles. The study has been carried out on samples having $\mu$-talc weight fractions covering the range $3-30 \%$. In the context of optimizing the crystallinity ratio of the polypropylene matrix in the composites, calorimetric experiments have been planned using a full factorial design. The results were statistically processed by analysis of the variance via mathematical models for predicting the crystallinity ratio in relation to the cooling rate and the filler ratio. Contour graphs have been plotted to determine the effect of each parameter on crystallinity. The cooling rate proved to have a significantly stronger influence on crystallinity than the type and content of filler.
\end{abstract}

Keywords: polymer composites, polypropylene composite, micro-talc, crystallinity, ANOVA method

\section{Introduction}

Isotactic polypropylene (iPP) filled with mineral particles such as calcium carbonate $\left(\mathrm{CaCO}_{3}\right)$ or with short glass fibers has been the subject of a lot of research [1-8]. The role of fillers in polymer based composites is multiple: it helps reducing the composite cost as it is generally less expensive than the polymer, but it also contributes to improving the mechanical performances and the physical properties if properly dispersed in the polymer matrix.

Isotactic polypropylene (iPP) is one of the most widely used semi-crystalline polymer for structural applications in the automotive industry, household appliances, construction, packaging, ropes, etc.
Mineral fillers proved to provide a toughening effect on iPP bulk pieces due to the ability to initiate elementary plasticity processes at the particle-matrix interface [3-8].

Since the early 80 's, profuse studies have been devoted to the mechanical reinforcement of iPP by nanofillers such as clay [9-11]. Such kinds of nanofillers were shown to noticeably improve the fireresistance of thermoplastic polymers [12] in addition to the mechanical performances. In the case of polymer matrices such as iPP having poor if any interaction with the nanofillers, surface treatment techniques of the nanoparticles were required as well as

\footnotetext{
${ }^{*}$ Corresponding author, e-mail: sathahamid@yahoo.fr

(C) BME-PT
} 
specific preparation methods involving the use of compatibilizing agents.

Among mineral fillers, talc proved to have a good potential of development for iPP-based composites, noticeably in the automotive industry [13-17]. It appeared very soon that talc displayed a strong nucleating effect for iPP $[14,19-23]$ due to specific physico-chemical interactions between the filler and the polymer matrix that promote epitaxial crystallization [14, 24-27]. This effect was significantly more pronounced than for other common fillers such as $\mathrm{CaCO}_{3}$ or kaolin and therefore give rise to better improvement of mechanical properties [14, 18]. This property makes talc able to be easily incorporated in iPP matrix without the use of a chemical surface treatment $[14,17,22]$, though the use of such treatment was reported to be efficient for dispersion of very fine particles at high loading [28-34].

It is worth noticing that talc reduces the efficiency of heat-stabilizing agents in iPP-based composites and by the way the fire-resistance of these composites $[35,36]$. However, a significant advantage of talc compared to $\mathrm{CaCO}_{3}$ or kaolin from a practical viewpoint is that it is much less abrasive for the extruder during the compounding and injection-molding stages.

Works regarding the mechanical reinforcement of iPP with talc have been orientated towards submicronic powders, i.e. intermediate size between conventional and nanometric fillers [15-17]. Using such filler particles with sub-micronic size enables to increase the specific area of the filler with respect to the former kind of fillers and to overcome the quite common problem of exfoliation and dispersion of the second kind of fillers. Besides, unlike $\mathrm{CaCO}_{3}$ and kaolin, $\mu$-talc has been developed as a lamellar-like filler thanks to a specific delamination technique from the producer that provides better reinforcing capacities at equivalent volume fraction [17, 37], owing to a very good dispersion that prevents the detrimental formation of aggregates [38]. It was shown in a previous study that the combination of the nucleating effect and the lamellar-like shape of $\mu$-talc particles generates a rigid percolating network of polymer crystallites and filler particles that contributes to the enhancement of the composite stiffness [36]. However, a possible drawback of the nucleation ability of talc on iPP is a reduced toughness due to the increase of crystallinity [39].
Therefore, it appears that the structure-property relationships of $\mu$-talc-reinforced iPP deserved further studies. The aim the present work was to investigate the effect of incorporation of $\mu$-talc on the crystallization potential of an iPP matrix in comparison with conventional PP composites with standard talc particles having a 3-times lower specific surface area. The cooling rate from the melt is also under concern in this study since it is well known to significantly influence the crystallization capabilities of semi-crystalline polymers, especially polypropylene [40-42]. A numerical analysis of the data has been used to optimize the composite crystallinity in relation to the filler ratio and the cooling rate.

\section{Experimental}

\subsection{Materials}

The polymer under investigation in this work is an isotactic polypropylene (iPP) from Solvay (Brussels, Belgium) with an isotacticity index of $96 \%$ according to the manufacturer. The weight-average molar mass was $M_{\mathrm{w}}=380000 \mathrm{~g} / \mathrm{mol}$ and the polydispersity index $I P=12$, as determined by size exclusion chromatography. The sub-micronic size talc $(\mu$-talc) without any surface treatment was supplied by Imerys Talc (Luzenac, France) under trade name HAR ${ }^{\circledR}$ Talc (High Aspect Ratio Talc). This new kind of filler was produced by delamination milling instead of gridding or micronizing. Standard talc (S-talc) was also used for the sake of comparison. The specific area of the present $\mu$-talc is $17 \mathrm{~m}^{2} / \mathrm{g}$ as compared to $6 \mathrm{~m}^{2} / \mathrm{g}$ for S-talc, using the Brunauer-Emmett-Teller method, according to the manufacturer. The average aspect ratio of the platelets, 5.5 and 1.3 for $\mu$-talc and S-talc respectively, was determined by scanning electron microscopy. All the composites were compounded by Multibase/Dow Corning (Saint Laurent du Pont, France) without compatibilizing agent using a Clextral BC21 twin screw extruder (Firminy, France) of length $1200 \mathrm{~mm}$ and diameter $25 \mathrm{~mm}$, the temperature being $180-210^{\circ} \mathrm{C}$ between feeder and die. The composites were finally injection-molded into $2 \mathrm{~mm}$ thick sheets.

The actual filler ratio of the various composites was precisely determined after compounding by means of thermogravimetry [37]. The actual ratio was very close to the nominal value adjusted at the stage of compounding, the standard deviation not exceeding $1 \%$, so that the nominal values were taken into account in this study. 


\subsection{Thermogravimetric analysis}

Thermogravimetric analysis (TGA) was performed on a Shimadzu DTG60 apparatus (Kyoto, Japan) under nitrogen gas flow. The heating rate was $10^{\circ} \mathrm{C} / \mathrm{min}$ over the temperature range $25-650^{\circ} \mathrm{C}$. The sample weight was about $10 \mathrm{mg}$.

\subsection{Differential scanning calorimetry}

Differential scanning calorimetry (DSC) was carried out on a SETARAM apparatus (Lyon, France), model LABSYS evo. The temperature and heat flow scales were calibrated using high purity indium at a heat rate of $10^{\circ} \mathrm{C} / \mathrm{min}$. The samples of about $10 \mathrm{mg}$ were heated up from 25 to $210^{\circ} \mathrm{C}$ and held at $210^{\circ} \mathrm{C}$ for $5 \mathrm{~min}$ in order to erase surviving iPP nuclei and thermal history due to processing. This methodology enabled determining the actual nucleating effect of $\mu$-talc. The samples were then cooled down to $25^{\circ} \mathrm{C}$ at various cooling rates in the range $2-40^{\circ} \mathrm{C} / \mathrm{min}$. Subsequent heating was performed at $10^{\circ} \mathrm{C} / \mathrm{min}$ in order to record the melting endotherm and determine the melting enthalpy. The crystal weight fraction was then computed from Equation (1):

$X_{\mathrm{c}}=\frac{\Delta H_{\mathrm{f}}}{\Delta H_{\mathrm{f}}^{\circ}}$

where $\Delta H_{\mathrm{f}}$ is the melting enthalpy of the polymer and $\Delta H_{\mathrm{f}}{ }^{\circ}=207 \mathrm{~J} / \mathrm{g}$ is the melting enthalpy of perfectly crystalline PP in the $\alpha$-crystal form [43]. In the case of composites, the actual weight fraction of the matrix polymer was taken into account.

\subsection{Wide-angle $X$-ray scattering}

Wide-angle X-ray scattering (WAXS) experiments were carried out at room temperature in transmission mode on a laboratory bench equipped with a Rigaku rotating $\mathrm{Cu}$-anode (Tokyo, Japan) operated at $100 \mathrm{kV}$ and $40 \mathrm{~mA}$. The X-ray beam was collimated with Göbel mirrors from Xenocs (Grenoble, France) that provided a monochromatic $\mathrm{Cu}-\mathrm{K} \alpha$ radiation (wavelength $=0.154 \mathrm{~nm}$ ) and parallel point focusing thanks to two pairs of anti-scattering slits. The 2D-WAXS patterns were recorded on a SCX2D-CCD camera from Princeton Instruments (Trenton NJ, USA). Data corrections were performed for transmission coefficient and background scattering. Azimuthal integration of the 2D patterns was performed using FitD2 software in order to get intensity profiles as a function of the scattering angle. This enabled to characterize the crystalline texturing of the samples

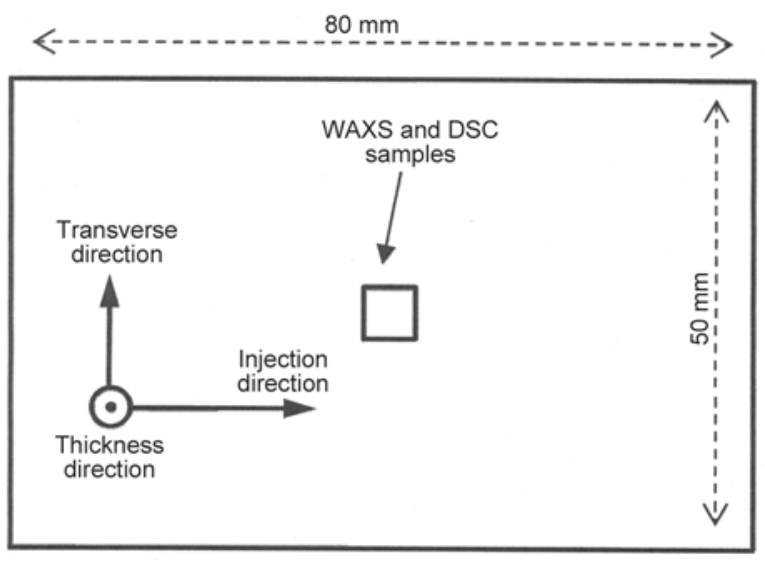

Figure 1. Schematic of the injection-moulded sheet and characteristic directions

induced by the injection-molding process in addition to the identification of their crystalline form. The samples were punched out from the sheets as shown in Figure 1. All samples were analyzed with the X-ray beam parallel to each of the 3 main directions, i.e. injection, transverse and thickness directions.

\subsection{Scanning electron microscopy}

Scanning electron microscopy (SEM) experiments were performed on a JOEL JSM 840A apparatus (Tokyo, Japan) in topographic mode at an acceleration voltage of $20 \mathrm{kV}$. Observations were made from the metal-coated surface of samples broken in liquid nitrogen. The microscope was equipped with an energy-dispersive X-ray (EDX) device that enabled identifying the elements from the talc platelets.

\subsection{Design and planning of experiments}

A design of experiments (DOE) approach was adopted for optimizing the crystallinity ratio, the two variables being the filler ratio and the cooling rate. The aim of this analysis was to identify the statistical relevance of the factors under investigation and their interactions and consequences on the response [4447]. The ANOVA variance analysis was used to determine the mathematical law. The 3D response surfaces (RS) were constructed by using the DesignExpert-8 statistics software.

Using the RS method enables 1) to model the response $Y$ under consideration as a function of the independent variables $X_{1}, X_{2}, \ldots, X_{\mathrm{i}}, \ldots$ and 2) to determine the interaction of these variables and their respective influence on the response $Y$. The second order regression used for the modelling is given by Equation (2): 


$$
Y=a_{0}+\sum_{\mathrm{i}=1}^{\mathrm{k}} a_{\mathrm{i}} X_{\mathrm{i}}+\sum_{\mathrm{i}=1}^{\mathrm{k}} a_{\mathrm{ii}} X_{\mathrm{i}}^{2}+\sum_{\mathrm{i}<\mathrm{j}}^{\mathrm{k}} a_{\mathrm{ij}} X_{\mathrm{i}} X_{\mathrm{j}}
$$

where $k$ is the number of independent variable parameters. In the present study, the response $Y$ is featuring the crystallinity ratio while the independent variables $X_{1}$ and $X_{2}$ hold for the cooling rate, $C_{\mathrm{R}}$, and the filler ratio, $F_{\mathrm{R}}$.

The strategy of planning of the experiments aims at carrying out the experiments in an optimal way for the modelling. The number of trials, $N$, is related to the number of variables, $k$, and the level of variation of these variables, $q$, via Equation (3):

$N=q^{\mathrm{k}}$

In the present study, $k=2$ and $q=7$ according to Table 1 data, so that $N=49$. The variable values for the trials are listed in Table 1.

Table 1. Data of the planning of experiments

\begin{tabular}{|c|c|c|}
\hline Level & $\begin{array}{c}\boldsymbol{C}_{\mathbf{R}} \\
{\left[{ }^{\circ} \mathbf{C} / \mathbf{m i n}\right]}\end{array}$ & $\begin{array}{c}\boldsymbol{F}_{\mathbf{R}} \\
{[\mathbf{\%}]}\end{array}$ \\
\hline 1 & 2 & 0 \\
\hline 2 & 5 & 3 \\
\hline 3 & 10 & 5 \\
\hline 4 & 15 & 7 \\
\hline 5 & 20 & 10 \\
\hline 6 & 30 & 20 \\
\hline 7 & 40 & 30 \\
\hline
\end{tabular}

\section{Experimental results}

In the previous study it was clearly shown that iPP/ $\mu$-talc composites exhibit significantly enhanced mechanical properties as compared to iPP/S-talc composites, at equivalent filler loading [36]. Only the thermal and structural behavior of the iPP/ $\mu$-talc composites will be addressed here, in comparison with the $\mathrm{iPP} / \mathrm{S}$-talc relatives.

\subsection{Thermogravimetric analysis}

Figure 2 shows the loss of mass plotted versus temperature. The residual mass of the samples after heating beyond $550^{\circ} \mathrm{C}$ is very close to that expected from the weight fraction of filler introduced at the processing stage, for all composites. Another observation from Figure 2 is that the curves gradually shift to higher temperature with increasing talc content indicating an improved resistance to thermal decomposition. Moreover, the shift of the curves for the $\mu$-talc composites is more notable than those for the industrial talc composites at the same filler loading. This

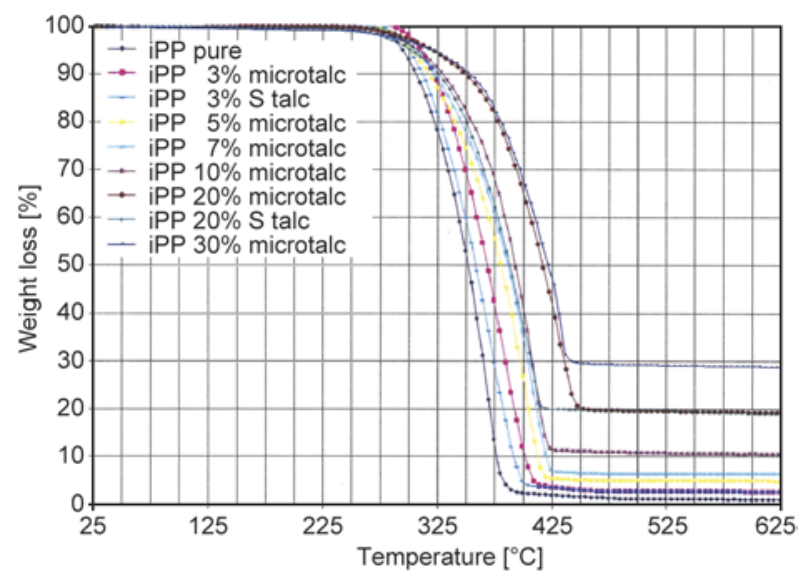

Figure 2. Weight loss of the iPP/ $\mu$-talc composites as a function of temperature

emphasizes the benefiting effect of $\mu$-talc compared to conventional talc from the viewpoint of fireresistance owing to its higher specific surface area that enhances the intumescence activity [26].

\subsection{Structural characterization}

Figure 3 reports the DSC cooling traces of iPP and iPP/ $\mu$-talc composites containing 10 and $30 \%$ of $\mu$-talc. The gradual shift to higher temperature of the crystallization exotherm with increasing $\mu$-talc content clearly reveals the nucleating effect of the talc particles that promotes an early initial crystallization of the PP matrix. Regarding the peak of the exotherm that is more relevant to the global crystallization rate including nucleation and growth, the very slight difference between the 10 and $30 \% \mu$-talc composites (Figure 3 ) suggests that a hindrance to the global crystallization occurs at high $\mu$-talc loading. Such a phenomenon has been reported to occur in nanocom-

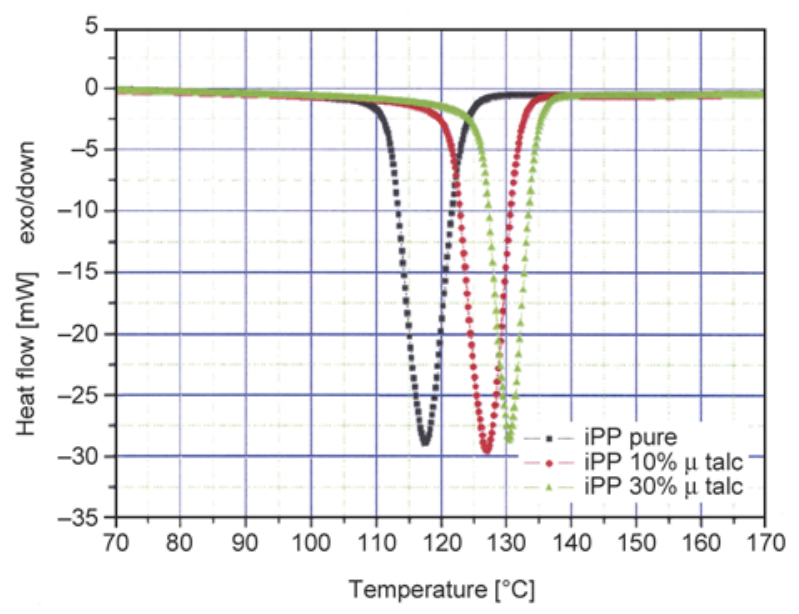

Figure 3. DSC crystallization curves of pure iPP and the composites $\mathrm{iPP} / 10 \% \mu$-talc and $\mathrm{iPP} / 30 \% \mu$-talc upon cooling at $10^{\circ} \mathrm{C} / \mathrm{min}$ from $210^{\circ} \mathrm{C}$ 
posites as well as conventional composites based on various semi-crystalline polymer matrices [48-54]. The current explanation is that at high loads the filler particles generate a physical barrier to the crystal lamella growth and thus limit the crystallization efficiency. This point will be further discussed regarding the effect of $\mu$-talc content on the crystallinity ratio.

The nucleating effect of $\mu$-talc is compared in Figure 4 to that of S-talc through the DSC cooling traces of the composites for the same filler loading value $F_{\mathrm{R}}=20 \%$ and same cooling rate $C_{\mathrm{R}}=$ $10^{\circ} \mathrm{C} / \mathrm{min}$. The shift to high temperature of the crystallization exotherm is slightly greater for $\mu$-talc, indicating better nucleating effect of the latter one due to its 3-fold higher specific surface area compared to S-talc.

The WAXS intensity profiles along 3 directions of the parallelepipedic samples of iPP and the iPP/7\% $\mu$-talc composite are reported in Figures 5 and 6. Only the main reflections of the monoclinic $\alpha$-form of iPP are observed for both the pure sample and the composite. This is consistent with previous reports that talc is an $\alpha$-nucleating agent for iPP [19-27]. The 3 intensity profiles of the pure iPP display a great similarity relevant of a structural isotropy (Figure 5). In contrast the strongly different profiles along for the iPP matrix in the $\mathrm{iPP} / 7 \% \mu$-talc composite are indicative of a strong crystalline texturing due to both the injection-molding and nucleating effect (Figure 6). Particularly, the very weak intensity of the (040) reflection of iPP in the WAXS profile through the thickness is a clear indication that the iPP chains are lying in the sample plane [23-27]. Moreover, the total absence of the

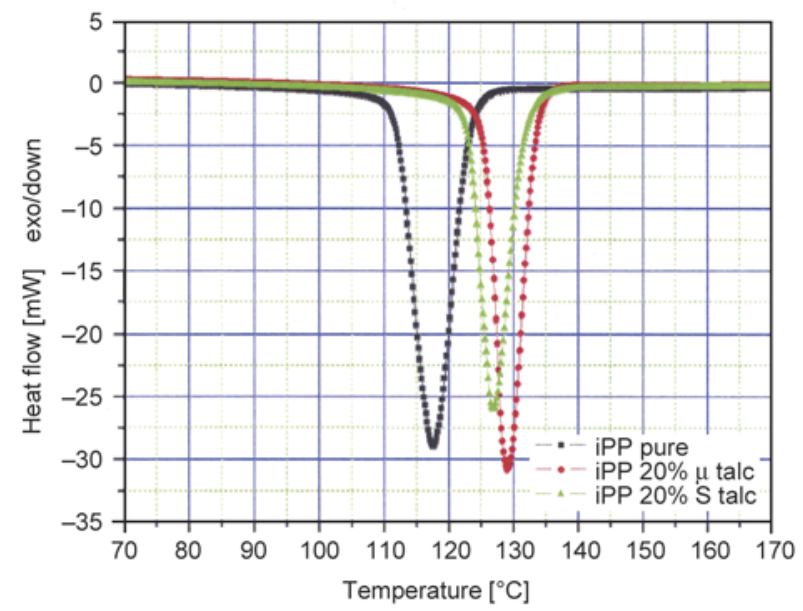

Figure 4. DSC crystallization curves of pure iPP and the composites iPP $/ 20 \% \mu$-talc and $\mathrm{iPP} / 20 \% \mathrm{~S}$-talc upon cooling at $10^{\circ} \mathrm{C} / \mathrm{min}$ from $210^{\circ} \mathrm{C}$

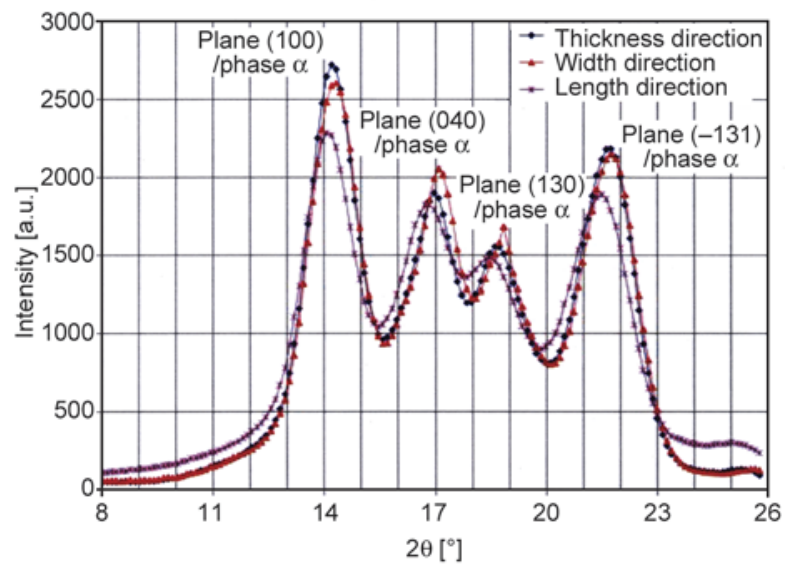

Figure 5. WAXS intensity profiles of pure iPP (injectionmolding)

(002) reflection of talc on the WAXS profile through the sample thickness (Figure 6) reveals that the talc platelets are also lying within the sample plane. Indeed, the (002) planes characteristic of the silicate sheets of talc stand along the larger dimensions of the talc platelets. The combination of this crystallographic characteristic of the talc platelets and their nucleating effect results in an orientation of the iPP crystals nearly normal to the talc platelets [23-27]. This concomitance of orientation of the chains and the talc platelets is a common feature of injectionmolded composites reinforced with filler of high aspect ratio which tend to align along the flow direction [27, 33, 55-57]. In the case of composites with lamellar fillers, this phenomenon is enhanced by to the so-called shear-amplification effect [58].

The shear-induced nucleation can compete with filler-induced nucleation [59] and may even prevail on it [33]. In the present study, the thermal treatment

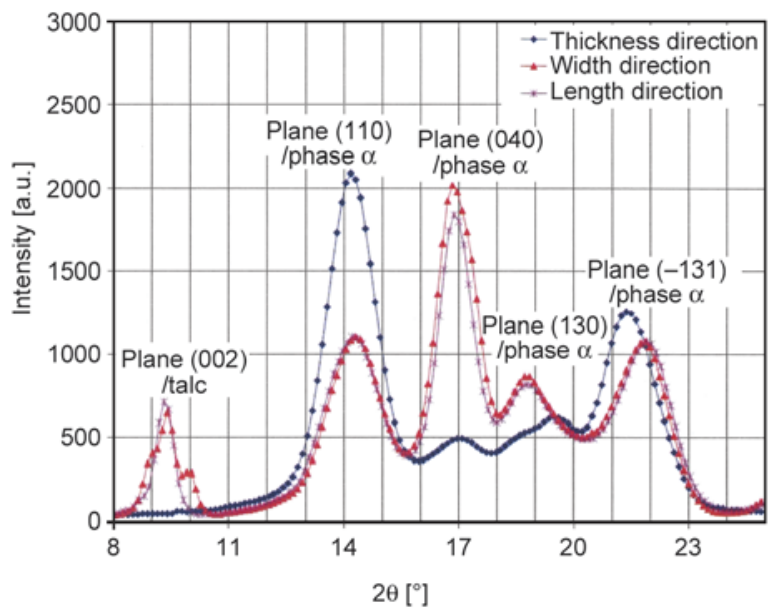

Figure 6. WAXS intensity profiles of the iPP/7\% $\mu$-talc composite (injection-molding) 
of the samples at $T=210^{\circ} \mathrm{C}$ for $5 \mathrm{~min}$ prior to the DSC crystallization experiments was carried out in order to erase any shear-induced chain orientation due to processing. Therefore, the sensitivity of the crystallization kinetics of the iPP/ $\mu$-talc composites to the filler content can be assigned to the $\mu$-talc surface nucleation due to favorable surface free energy [26]. Scanning electron ricroscopy was also used for further structural characterization of the composites. Figure 7 shows a SEM image from the facture surface

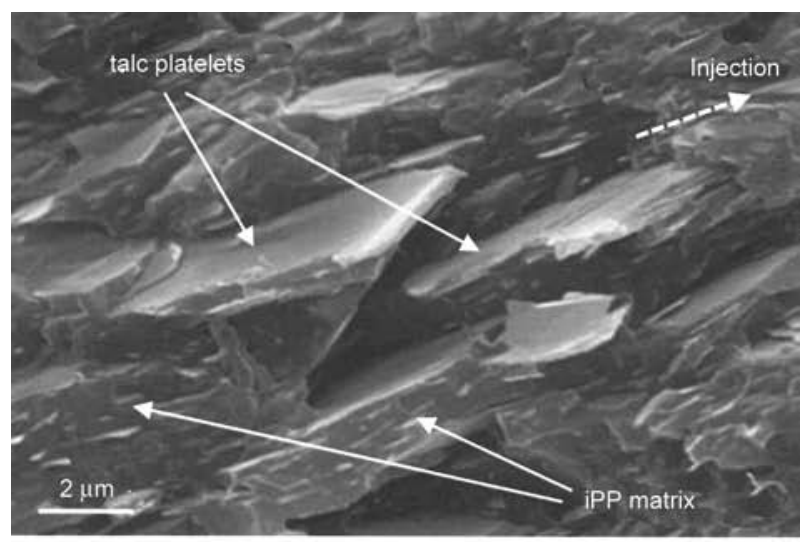

a)

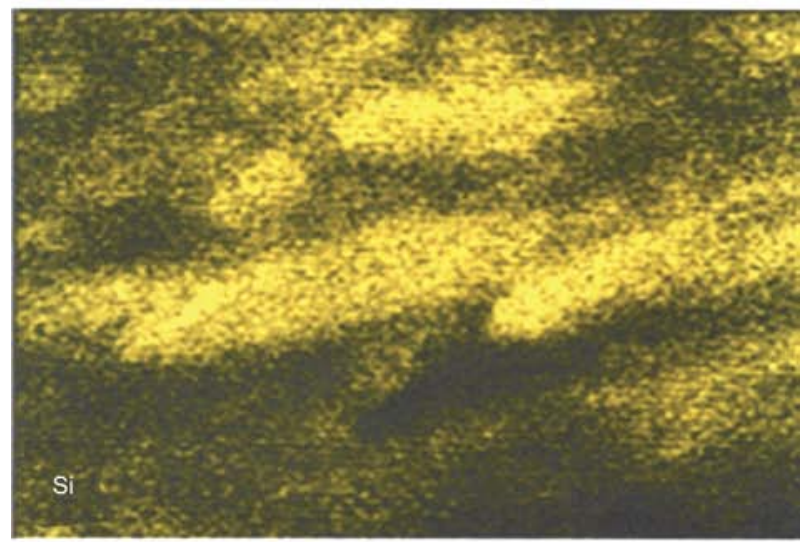

b)

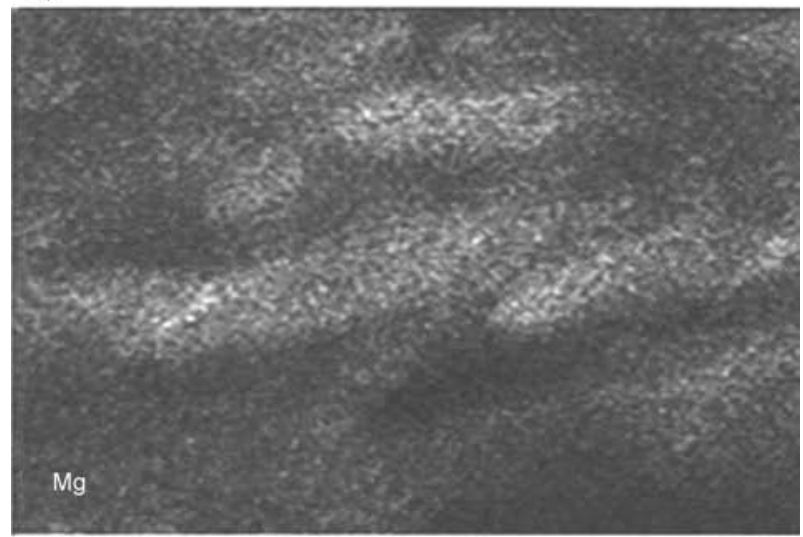

c)

Figure 7. SEM image (a) from the center of a cross-section of an injection-molded iPP $/ 30 \% \mu$-talc and corresponding EDX images of the $\mathrm{Si}(\mathrm{b})$ and $\mathrm{Mg}$ (c) atomic distributions in the talc platelets of an iPP $/ 30 \% \mu$-talc composite. The talc platelets appear to be fairly well dispersed and aligned along the injection direction. Better identification of the talc platelets and confirmation of both their dispersion and orientation is provided by the corresponding EDX images showing the distributions of the $\mathrm{Si}$ and $\mathrm{Mg}$ elements from talc.

\subsection{Crystallinity versus talc loading and cooling rate}

Crystallinity has been determined for the 49 samples of the series, i.e. pure iPP together with 6 composites of different $\mu$-talc loadings crystallized at 7 different cooling rates. All the XC data are reported in Table 2. An examination of these data reveals that $X_{\mathrm{C}}$ decreases with increasing $C_{\mathrm{R}}$ for a given $F_{\mathrm{R}}$. Less time is afforded to the iPP matrix for crystallizing in its optimal temperature range $\left(110<T_{\mathrm{c}}{ }^{\max }<130^{\circ} \mathrm{C}\right.$, see Figure 3) when $C_{\mathrm{R}}$ is high. Conversely, $X_{\mathrm{C}}$ increases with $F_{\mathrm{R}}$ at a given $C_{\mathrm{R}}$ since higher $F_{\mathrm{R}}$ provides more particle surface for iPP nucleation. However, it can be seen in Table 2 that the $X_{\mathrm{C}}$ evolution is different if considering the sensitivity to $C_{\mathrm{R}}$ of the various materials. At low cooling rate, i.e. $C_{\mathrm{R}}=$ $2{ }^{\circ} \mathrm{C} / \mathrm{min}$, the rather high $X_{\mathrm{C}}$ data increase quickly in a first step with increasing $F_{\mathrm{R}}$ then tend to level off for $F_{\mathrm{R}}>7 \%$. In contrast, at high $C_{\mathrm{R}}$, i.e. $C_{\mathrm{R}}=$ $40{ }^{\circ} \mathrm{C} / \mathrm{min}$, the significantly lower $X_{\mathrm{C}}$ values display a roughly linear increase with $F_{\mathrm{R}}$ without leveling off. As proposed in the previous subsection, and borrowing from several reports regarding polymer-clay nanocomposites, this finding may be attributed to a physical barrier effect or steric hindrance of the $\mu$-talc platelets to the growth of iPP crystal lamellae at high $F_{\mathrm{R}}$ and low $C_{\mathrm{R}}$ when crystallinity is high. The barrier effect of the $\mu$-talc platelets would be less effective at high $C_{\mathrm{R}}$ due to less steric hindrance to the crystal growth when crystallinity is low.

For the sake of comparison, crystallinity data for Stalc composites are reported in Table 2 as a function of $C_{\mathrm{R}}$, for two $F_{\mathrm{R}}$ values 3 and $20 \%$. Though differences are not dramatic between the two kinds of composites, the $X_{\mathrm{C}}$ data are systematically higher for the $\mu$-talc composites, irrespective of $C_{\mathrm{R}}$ and $F_{\mathrm{R}}$, which confirms the better nucleating effect of $\mu$-talc due to higher specific area.

\subsection{Statistical analysis and modeling}

The statistical analysis of the response to any kind of experiment is a useful tool for probing the incidence 
of the various experimental or entry parameters on the response. A numerical relation can be established between the response and the entry parameters [16, 43-45]. The numerical values of the response can be

Table 2. Crystallinity data from experimental plan ( $\mu$ and $\mathrm{S}$ superscripts hold for $\mu$-talc and S-talc composites)

\begin{tabular}{|c|c|c|c|c|}
\hline Run & $\begin{array}{c}\boldsymbol{C}_{\mathrm{R}} \\
{\left[{ }^{\circ} \mathbf{C} / \mathbf{m i n}\right]}\end{array}$ & $\begin{array}{c}F_{\mathrm{R}} \\
{[\%]}\end{array}$ & $\begin{array}{l}X_{C^{\mu}} \\
{[\%]}\end{array}$ & $\begin{array}{l}X_{\mathrm{C}}^{\mathrm{S}} \\
{[\%]}\end{array}$ \\
\hline 1 & 2 & 0 & 53.8 & - \\
\hline 2 & 2 & 3 & 54.3 & 54.0 \\
\hline 3 & 2 & 5 & 55.0 & - \\
\hline 4 & 2 & 7 & 59.2 & - \\
\hline 5 & 2 & 10 & 59.6 & - \\
\hline 6 & 2 & 20 & 61.2 & 58.2 \\
\hline 7 & 2 & 30 & 62.2 & - \\
\hline 8 & 5 & 0 & 51.4 & - \\
\hline 9 & 5 & 3 & 53.7 & 52.7 \\
\hline 10 & 5 & 5 & 54.2 & - \\
\hline 11 & 5 & 7 & 56.7 & - \\
\hline 12 & 5 & 10 & 59.4 & - \\
\hline 13 & 5 & 20 & 61.0 & $(58.5)$ \\
\hline 14 & 5 & 30 & 61.9 & - \\
\hline 15 & 10 & 0 & 49.2 & - \\
\hline 16 & 10 & 3 & 51.5 & 50.5 \\
\hline 17 & 10 & 5 & 53.2 & - \\
\hline 18 & 10 & 7 & 53.4 & - \\
\hline 19 & 10 & 10 & 53.5 & - \\
\hline 20 & 10 & 20 & 54.9 & 53.5 \\
\hline 21 & 10 & 30 & 58.8 & - \\
\hline 22 & 15 & 0 & 44.5 & - \\
\hline 23 & 15 & 3 & 47.4 & 46.1 \\
\hline 24 & 15 & 5 & 49.8 & - \\
\hline 25 & 15 & 7 & 50.2 & - \\
\hline 26 & 15 & 10 & 53.0 & - \\
\hline 27 & 15 & 20 & 53.5 & 52.8 \\
\hline 28 & 15 & 30 & 57.2 & - \\
\hline 29 & 20 & 0 & 43.9 & - \\
\hline 30 & 20 & 3 & 44.0 & 43.6 \\
\hline 31 & 20 & 5 & 45.1 & - \\
\hline 32 & 20 & 7 & 46.9 & - \\
\hline 33 & 20 & 10 & 48.4 & - \\
\hline 34 & 20 & 20 & 52.2 & 48.2 \\
\hline 35 & 20 & 30 & 55.9 & - \\
\hline 36 & 30 & 0 & 35.2 & - \\
\hline 37 & 30 & 3 & 37.3 & 36.4 \\
\hline 38 & 30 & 5 & 38.5 & - \\
\hline 39 & 30 & 7 & 42.4 & - \\
\hline 40 & 30 & 10 & 42.6 & - \\
\hline 41 & 30 & 20 & 43.9 & 42.1 \\
\hline 42 & 30 & 30 & 48.8 & - \\
\hline 43 & 40 & 0 & 34.5 & - \\
\hline 44 & 40 & 3 & 36.6 & 35.7 \\
\hline 45 & 40 & 5 & 37.0 & - \\
\hline 46 & 40 & 7 & 37.6 & - \\
\hline 47 & 40 & 10 & 37.9 & - \\
\hline 48 & 40 & 20 & 39.3 & 37.8 \\
\hline 49 & 40 & 30 & 43.4 & - \\
\hline
\end{tabular}

then compared to the experimental data. The Design Expert 8 software was used in this study in combination with the ANOVA variance analysis.

The numerical expression for the crystallinity as a function of the experimental parameters derived from Equation (2) is given by Equation (4):

$$
\begin{aligned}
X_{\mathrm{C}}= & +53.77850-0.42080 \cdot C_{\mathrm{R}}+1.02231 \cdot F_{\mathrm{R}}+ \\
& +3.89570 \cdot 10^{-3} \cdot C_{\mathrm{R}} \cdot F_{\mathrm{R}}-0.015739 \cdot C_{\mathrm{R}}{ }^{2}- \\
& -0.047613 \cdot F_{\mathrm{R}}{ }^{2}-3.31598 \cdot 10^{-4} \cdot C_{\mathrm{R}}{ }^{2} \cdot F_{\mathrm{R}}{ }^{+} \\
& +3.35287 \cdot 10^{-4} \cdot C_{\mathrm{R}} \cdot F_{\mathrm{R}}{ }^{2}+3.52478 \cdot 10^{-4} \cdot C_{\mathrm{R}}{ }^{3}+ \\
& +7.63055 \cdot 10^{-4} \cdot F_{\mathrm{R}}{ }^{3}
\end{aligned}
$$

with a regression coefficient $R^{2}=98.5$.

The residuals reported in Figure 8 for the 49 experiments or runs do not exceed $2.5 \%$ of the $X_{\mathrm{C}}$ value and are randomly distributed about the $X_{\mathrm{C}}$ value of every run. Moreover, Figure 9 shows that the residues fairly obey a normal law distribution.

On Figure 10 is shown the 2D mapping of the predicted crystallinity as a function of $C_{\mathrm{R}}$ and $F_{\mathrm{R}}$ together with the experimental data. The blue to red color range accounts for the full crystallinity range of the present study $34.5 \%<X_{\mathrm{C}}<62.2 \%$. The isocolor domains stand for the $C_{\mathrm{R}} / F_{\mathrm{R}}$ coupling that results in iso-crystallinity.

Figure 11 is a $3 \mathrm{D}$ diagram of $X_{\mathrm{C}}$ versus $C_{\mathrm{R}}$ and $F_{\mathrm{R}}$. This figure shows that, in the experimentally accessible ranges of $C_{\mathrm{R}}$ and $F_{\mathrm{R}}, X_{\mathrm{C}}$ is much more sensitive to $C_{\mathrm{R}}$ than to $F_{\mathrm{R}}$. Indeed, in the high $X_{\mathrm{C}}$ domain, the red zone extends more along the $F_{\mathrm{R}}$ range than along the $C_{\mathrm{R}}$ range. Similarly, in the low $X_{\mathrm{C}}$ domain,

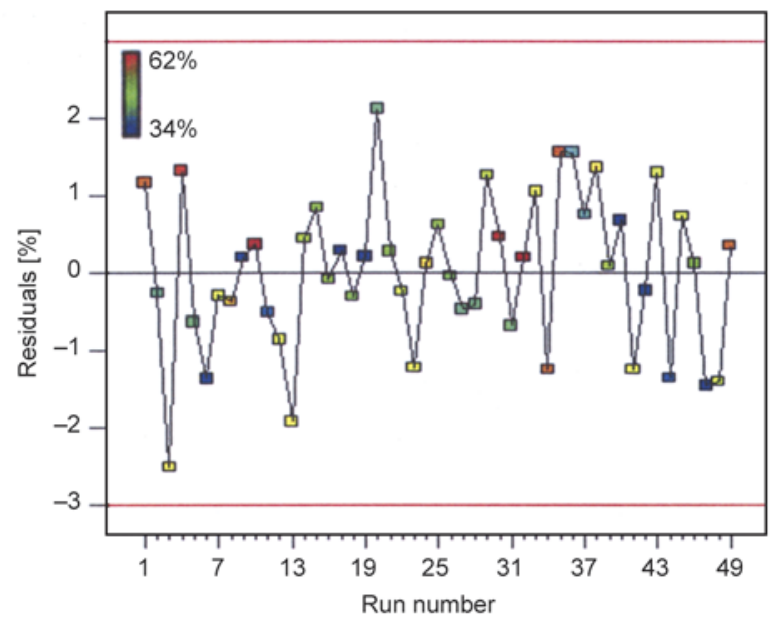

Figure 8. Residuals for the crystallinity ratio from the statistical analysis (same Run $\mathrm{N}^{\circ}$ as in Table 2; symbol color holds for the crystallinity ratio) 


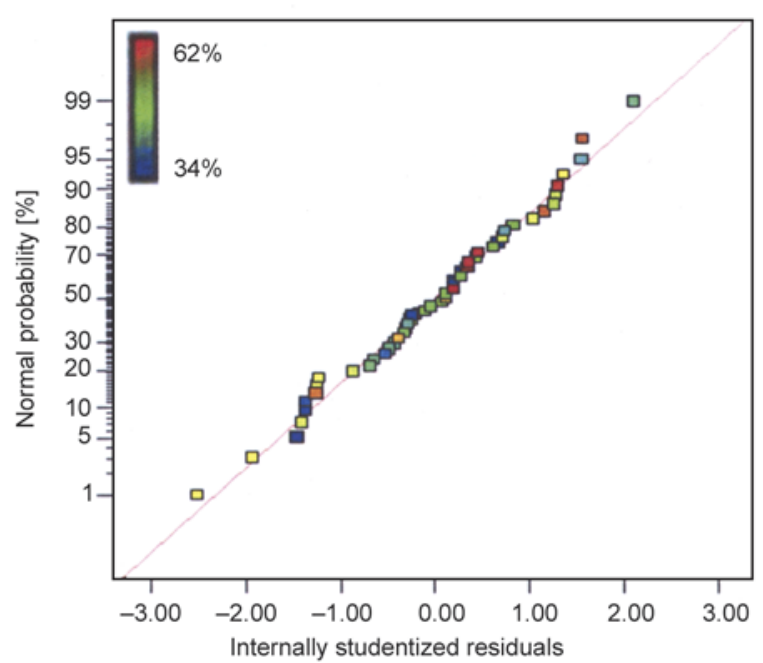

Figure 9. Residual distribution of the crystallinity ratio (same color scale as in Figure 8)

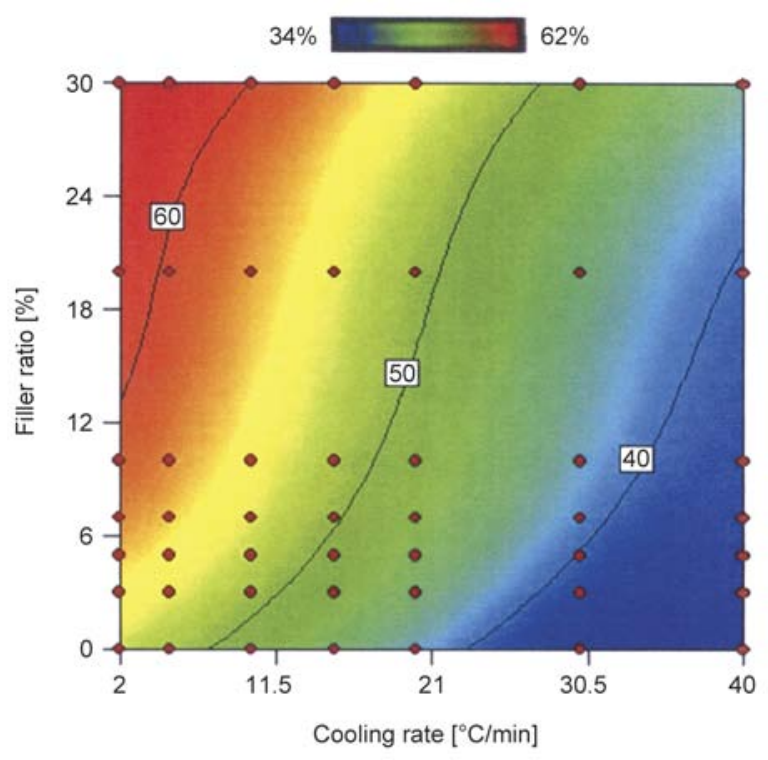

Figure 10. 2D mapping of the predicted crystallinity ratio versus $C_{\mathrm{R}}$ and $F_{\mathrm{R}}$ (the full lines stand for iso-crystallinity curves; symbols hold for experimental data)

the blue zone extends more along the $F_{\mathrm{R}}$ range than along the $C_{\mathrm{R}}$ range.

Figure 11 also reveals that at high talc loading, i.e. $F_{\mathrm{R}} \geq 20 \%, X_{\mathrm{C}}$ tends to saturate at its maximum value for $C_{\mathrm{R}} \leq 5^{\circ} \mathrm{C} / \mathrm{min}$ as judged from the nearly zero slope of the predicted $X_{\mathrm{C}}$ variation versus $F_{\mathrm{R}}$. Therefore, one cannot expect $X_{\mathrm{C}}>62.2 \%$ even with $\mu$-talc loadings $F_{\mathrm{R}} \gg 30 \%$. Similarly, the very low slope of the predicted $X_{\mathrm{C}}$ variation with $C_{\mathrm{R}}$ at low $C_{\mathrm{R}}$ values suggests that one may hardly expect $X_{\mathrm{C}}>$ $62.2 \%$ even if using $C_{\mathrm{R}} \ll 2{ }^{\circ} \mathrm{C} / \mathrm{min}$.

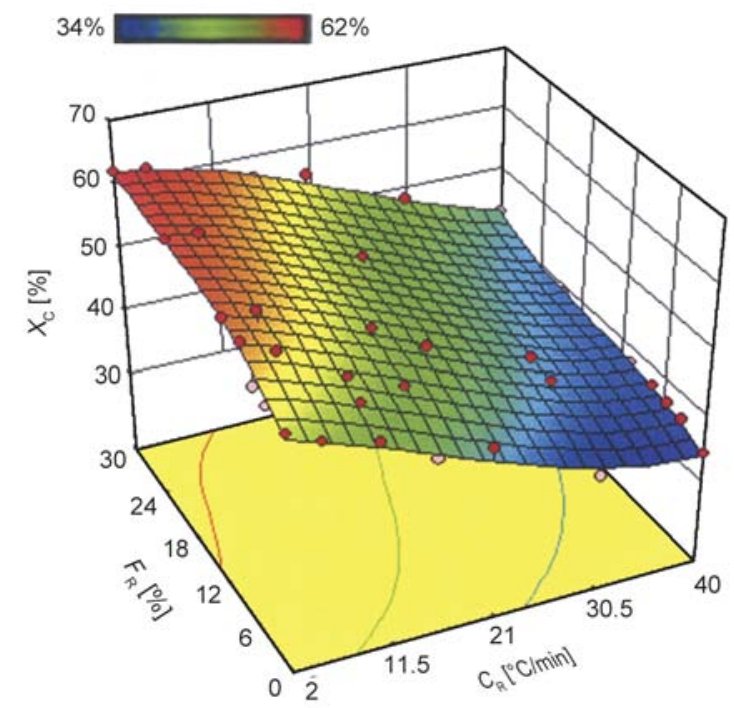

Figure 11. 3D surface plot of $X_{\mathrm{C}}$ versus $C_{\mathrm{R}}$ and $F_{\mathrm{R}}$

\section{Conclusions}

The thermal, microscopic and crystallographic study of iPP $/ \mu$-talc composites showed that $\mu$-talc is actually a nucleating agent of the iPP matrix, irrespective of potential shear-induced effects due to processing. This nucleating effect is somewhat more pronounced than for standard talc having a surface area about 3 times lower than that of $\mu$-talc. The combination of this nucleating effect with the injectiondriven orientation of the platelets generates a strong texturing of the samples.

The use of ANOVA analysis of a set of experimental data of crystallinity $\left(X_{\mathrm{C}}\right)$ for various values of the cooling rate $\left(C_{\mathrm{R}}\right)$ and various values of the filler content $\left(F_{\mathrm{R}}\right)$ allowed to draw a numerical 3D surface $X_{\mathrm{C}}=f\left(C_{\mathrm{R}}, F_{\mathrm{R}}\right)$ for predicting the crystallinity of the composites for any cooling rate and filler content with a confidence level greater than of $95 \%$. This $3 \mathrm{D}$ surface clearly shows the greater $X_{\mathrm{C}}$ sensitivity to $C_{\mathrm{R}}$ compared to $F_{\mathrm{R}}$. It also clearly showed the $X_{\mathrm{C}}$ saturation at low cooling rates $\left(C_{\mathrm{R}} \leq 5^{\circ} \mathrm{C} / \mathrm{min}\right)$ and high talc loading $\left(F_{\mathrm{R}} \geq 20 \%\right)$. Moreover, it appears that the strong sensitivity of iPP matrix to $F_{\mathrm{R}}$ does not shortcut the intrinsic sensitivity of iPP to $C_{\mathrm{R}}$, the two effects being clearly additive.

\section{Acknowledgements}

The authors are indebted to Multibase/Dow Corning (SaintLaurent du Pont, France) for the supply of the composites and the characteristics of the components, and to Dr. Patrick Prele from Multibase for fruitful discussions. 


\section{References}

[1] Karger-Kocsis J.: Polypropylene: Structure, blends and composites; Vol.3: Composites. Chapman and Hall, London (1994).

[2] Karian H. G.: Handbook of polypropylene and polypropylene composites. Marcel Dekker, New York (2003).

[3] McGenity P. M., Hooper J. J., Paynter C. D., Riley A. M., Nutbeem C., Elton N. J., Adams J. M.: Nucleation and crystallization of polypropylene by mineral fillers: Relationship to impact strength. Polymer, 33, 52155224 (1992).

DOI: 10.1016/0032-3861(92)90804-6

[4] Wilbrink M. W. L., Argon A. S., Cohen R. E., Weinberg M.: Toughenability of Nylon- 6 with $\mathrm{CaCO}_{3}$ filler particles: New findings and general principles. Polymer, 42, 10155-10180 (2001). DOI: $10.1016 / \mathrm{S} 0032-3861(01) 00548-1$

[5] Thio Y. S., Argon A. S., Cohen R. E., Weinberg M.: Toughening of isotactic polypropylene with $\mathrm{CaCO}_{3}$ particles. Polymer, 43, 3661-3674 (2002).

DOI: 10.1016/S0032-3861(02)00193-3

[6] Zuiderduin W. C. J., Westzaan C., Huétink J., Gaymans R. J.: Toughening of polypropylene with calcium carbonate particles. Polymer, 44, 261-275 (2003). DOI: $10.1016 / \mathrm{S} 0032-3861(02) 00769-3$

[7] Thio Y. S., Argon A. S., Cohen R. E.: Role of interfacial adhesion strength on toughening polypropylene with rigid particles. Polymer, 45, 3139-3147 (2004). DOI: $10.1016 /$ j.polymer.2004.02.064

[8] Hadal R. S., Dasari A., Rohrmann J., Misra R. D. K.: Effect of wollastonite and talc on the micromechanisms of tensile deformation in polypropylene composites. Materials Science and Engineering: A, 372, 296-315 (2004).

DOI: $10.1016 / \mathrm{j} . \mathrm{msea} .2004 .01 .003$

[9] Alexandre M., Dubois P.: Polymer-layered silicate nanocomposites: Preparation, properties and uses of a new class of materials. Materials Science and Engineering R: Reports, 28, 1-63 (2000).

DOI: $10.1016 / \mathrm{S} 0927-796 \mathrm{X}(00) 00012-7$

[10] Ray S. S., Okamoto M.: Polymer/layered silicate nanocomposites: A review from preparation to processing. Progress in Polymer Science, 28, 1539-1641 (2003). DOI: 10.1016/j.progpolymsci.2003.08.002

[11] Százdi L., Pozsgay A., Pukánszky B.: Factors and processes influencing the reinforcing effect of layered silicates in polymer nanocomposites. European Polymer Journal, 43, 345-359 (2007).

DOI: $10.1016 /$ j.eurpolymj.2006.11.005

[12] Bourbigot S., Duquesne S.: Fire retardant polymers: Recent developments and opportunities. Journal of Materials Chemistry, 17, 2283-2300 (2007).

DOI: $10.1039 / \mathrm{b} 702511 \mathrm{~d}$
[13] Naiki M., Fukui Y., Matsumura T., Nomura T., Matsuda M.: The effect of talc on the crystallization of isotactic polypropylene. Journal of Applied Polymer Science, 79, 1693-1703 (2001).

DOI: $10.1002 / 1097-4628(20010228) 79: 9<1693::$ AIDAPP190>3.0.CO;2-P

[14] Obata Y., Sumitomo T., Ijitsu T., Matsuda M., Nomura T.: The effect of talc on the crystal orientation in polypropylene/ethylene-propylene rubber/talc polymer blends in injection molding. Polymer Engineering and Science, 41, 408-416 (2001).

DOI: $10.1002 /$ pen. 10738

[15] Zhou Y., Mallick P.: Effects of temperature and strain rate on the tensile behavior of unfilled and talc-filled polypropylene. Part I: Experiments. Polymer Engineering and Science, 42, 2449-2460 (2002).

DOI: $10.1002 /$ pen. 11131

[16] Barbosa C. N., Simoes R., Franzen M., Viana J. C.: Thermomechanical environment characterisation in injection moulding and its relation to the mechanical properties of talc-filled polypropylene. Journal of Materials Science, 48, 2597-2607 (2013). DOI: $10.1007 / \mathrm{s} 10853-012-7052-4$

[17] Prêle P., von Tschammer A., Crépin-Leblond J.: An innovative masterbatch concept for automotive plastics using an extremely high aspect ratio talc. in 'Proceedings of the $22^{\text {nd }}$ World Automotive Congress: Plastics in Motion, Roma, Italy' p.25 (2007).

[18] Leong Y. W., Abu Bakar M. B., Ishak Z. A. M., Ariffin A., Pukánszky B.: Comparison of the mechanical properties and interfacial interactions between talc, kaolin, and calcium carbonate filled polypropylene composites. Journal of Applied Polymer Science, 91, 33153326 (2004). DOI: $10.1002 / a p p .13542$

[19] Menczel J., Varga J.: Influence of nucleating agents on crystallization of polypropylene I. Talc as a nucleating agent. Journal of Thermal Analysis, 28, 161-174 (1983). DOI: 10.1007/BF02105288

[20] Rybnikáŕ F.: Orientation in composite of polypropylene and talc. Journal of Applied Polymer Science, 38, 1479-1490 (1989).

DOI: 10.1002/app.1989.070380806

[21] de Medeiros E. S., Tocchetto R. S., de Carvalho L. H., Santos I. M. G., Souza A. G.: Nucleating effect and dynamic crystallization of a poly(propylene)/talc system. Journal of Thermal Analysis and Calorimetry, 66, 523-531 (2001). DOI: 10.1023/A:1013121102536

[22] Kocic N., Kretschmer K., Bastian M., Heidemeyer P.: The influence of talc as a nucleation agent on the nonisothermal crystallization and morphology of isotactic polypropylene: The application of the Lauritzen-Hoffmann, Avrami, and Ozawa theories. Journal of Applied Polymer Science, 126, 1207-1217 (2012).

DOI: 10.1002/app.36880 
[23] Choi W. J., Kim S. C.: Effects of talc orientation and non-isothermal crystallization rate on crystal orientation of polypropylene in injection-molded polypropylene/ethylene-propylene rubber/talc blends. Polymer, 45, 2393-2401 (2004).

DOI: $10.1016 /$ j.polymer.2004.01.058

[24] Fujiyama M., Wakino T.: Crystal orientation in injection molding of talc-filled polypropylene. Journal of Applied Polymer Science, 42, 9-20 (1991).

DOI: 10.1002 /app.1991.070420103

[25] Fujiyama M.: Crystal orientation in injection moldings of talc-filled polyolefins. International Polymer Processing, 13, 284-290 (1998).

DOI: $10.3139 / 217.980284$

[26] Ferrage E., Martin F., Boudet A., Petit S., Fourty G., Jouffret F., Micoud P., de Parseval P., Salvi S., Bourgerette C., Ferret J., Saint-Gerard Y., Buratto S., Fortune J. P.: Talc as nucleating agent of polypropylene: Morphology induced by lamellar particles addition and interface mineral-matrix modelization. Journal of Materials Science, 37, 1561-1573 (2002).

DOI: 10.1023/A:1014929121367

[27] Branciforti M. C., Oliveira C. A., de Sousa J. A.: Molecular orientation, crystallinity, and flexural modulus correlations in injection molded polypropylene/ talc composites. Polymers for Advanced Technologies, 21, 322-330 (2010). DOI: $10.1002 /$ pat. 1431

[28] Maiti S. N., Sharma K. K.: Studies on polypropylene composites filled with talc particles. Journal of Materials Science, 27, 4605-4613 (1992).

DOI: $10.1007 / \mathrm{BF} 01165994$

[29] Liu Z., Gilbert M.: Structure and properties of talcfilled polypropylene: Effect of phosphate coating. Journal of Applied Polymer Science, 59, 1087-1098 (1996). DOI: $10.1002 /($ SICI $) 1097-4628(19960214) 59: 7<1087$ $\because$ AID-APP5>3.3.CO;2-S

[30] Huneault M. A., Godfroy P. G., Lafleur P. G.: Performance of talc/ethylene-octene copolymer/polypropylene blends. Polymer Engineering and Science, 39, 11301138 (1999).

DOI: $10.1002 /$ pen. 11500

[31] Zhou X-P., Xie X-L., Yu Z-Z., Mai Y-W.: Intercalated structure of polypropylene/in situ polymerization-modified talc composites via melt compounding. Polymer, 48, 3555-3564 (2007).

DOI: 10.1016/j.polymer.2007.04.033

[32] Castillo L. A., Barbosa S. E., Capiati N. J.: Surface-modified talc particles by acetoxy groups grafting: Effects on mechanical properties of polypropylene/talc composites. Polymer Engineering and Science, 53, 89-95 (2013).

DOI: $10.1002 /$ pen.23243
[33] Fiorentino B., Fulchiron R., Duchet-Rumeau J., BounorLegaré V., Majesté J-C.: Controlled shear-induced molecular orientation and crystallization in polypropylene/talc microcomposites - Effects of the talc nature. Polymer, 54, 2764-2775 (2013).

DOI: $10.1016 /$ j.polymer.2013.03.057

[34] Fiorentino B., Fulchiron R., Bounor-Legare V., Majesté J-C., Leblond J. C., Duchet-Rumeau J.: Chemical modification routes of synthetic talc: influence on its nucleating power and on its dispersion state. Applied Clay Science, 110, 107-118 (2015). DOI: $10.1016 /$ j.clay.2015.02.026

[35] Rotzinger B.: Talc-filled PP: A new concept to maintain long term heat stability. Polymer Degradation and Stability, 91, 2884-2887 (2006).

DOI: $10.1016 /$ j.polymdegradstab.2006.09.008

[36] Duquesne S., Samyn F., Bourbigot S., Amigouet P., Jouffret F., Shen K.: Influence of talc on the fire retardant properties of highly filled intumescent polypropylene composites. Polymers for Advanced Technologies, 19, 620-627 (2008).

DOI: $10.1002 /$ pat.1127

[37] Frihi D., Masenelli-Varlot K., Vigier G., Satha H.: Mixed percolating network and mechanical properties of polypropylene/talc composites. Journal of Applied Polymer Science, 114, 3097-3105 (2009).

DOI: 10.1002/app.30890

[38] Paul D. R., Bucknall C. B.: Polymer blends, Vol. 2: Performance. Wiley, New York (2000).

[39] van der Wal A., Mulder J. J., Gaymans R. J.: Fracture of polypropylene: The effect of crystallinity. Polymer, 39, 5477-5481 (1998). DOI: $10.1016 / \mathrm{S} 0032-3861(97) 10279-8$

[40] Piccarolo S.: Morphological changes in isotactic polypropylene as a function of cooling rate. Journal of Macromolecular Science Part B: Physics, 31, 501-511 (1992).

DOI: $10.1080 / 00222349208215467$

[41] van Drongelen M., van Erp T. B., Peters G. W. M.: Quantification of non-isothermal, multi-phase crystallization of isotactic polypropylene: The influence of cooling rate and pressure. Polymer, 53, 4758-4769 (2012).

DOI: $10.1016 /$ j.polymer.2012.08.003

[42] Gahleitner M., Bernreitner K., Neiß1 W.: Correlations between rheological and mechanical properties of mineral filled polypropylene compounds. Journal of Applied Polymer Science, 53, 283-289 (1994).

DOI: $10.1002 / a p p .1994 .070530304$

[43] Wunderlich B.: Macromolecular physics, Vol.1: Crystal structure, morphology and defects. Academic Press, New York (1973).

[44] da Costa M. H., Ramos D. V., de Oliveira G. M.: Degradation of polypropylene (PP) during multiple extrusions: Thermal analysis, mechanical properties and analysis of variance. Polymer Testing, 26, 676-684 (2007).

DOI: $10.1016 /$ j.polymertesting.2007.04.003 
[45] Gu R., Kokta B. V.: Maximization of the mechanical properties of birch-polypropylene composites with additives by statistical experimental design. Journal of Thermoplastic Composite Materials, 23, 239-263 (2010).

DOI: $10.1177 / 0892705708103402$

[46] Hejazi I., Sharif F., Garmabi H.: Effect of material and processing parameters on mechanical properties of polypropylene/ethylene-propylene-diene-monomer/clay nanocomposites. Materials and Design, 32, 3803-3809 (2011).

DOI: 10.1016/j.matdes.2011.03.017

[47] Raja R. S., Manisekar K., Manikandan V.: Study on mechanical properties of fly ash impregnated glass fiber reinforced polymer composites using mixture design analysis. Materials and Design, 55, 499-508 (2014). DOI: $10.1016 /$ j.matdes.2013.10.026

[48] Chabert B., Chauchard J., Cinquin J.: DSC study of the non-isothermal crystallization of the PA66 matrix in glass fiber composites (in French). Makromolekulare Chemie. Macromolecular Symposia, 9, 99-111 (1987). DOI: 10.1002/masy.19870090112

[49] Valentini L., Biagiotti J., Kenny J. M., Santucci S.: Morphological characterization of single-walled carbon nanotubes-PP composites. Composites Science and Technology, 63, 1149-1153 (2003). DOI: $10.1016 / \mathrm{S} 0266-3538(03) 00036-8$

[50] Fornes T. D., Paul D. R.: Crystallization behavior of nylon 6 nanocomposites. Polymer, 44, 3945-3961 (2003).

DOI: $10.1016 / \mathrm{S} 0032-3861(03) 00344-6$

[51] Lincoln D. M., Vaia R. A., Krishnamoorti R.: Isothermal crystallization of nylon-6/montmorillonite nanocomposites. Macromolecules, 37, 4554-4561 (2004). DOI: $10.1021 / \mathrm{ma} 049768 \mathrm{k}$

[52] Yang Z., Huang S., Liu T.: Crystallization behavior of polyamide 11/multiwalled carbon nanotube composites. Journal of Applied Polymer Science, 122, 551-560 (2011). DOI: $10.1002 / a p p .34118$
[53] Zare Y., Garmabi H.: Nonisothermal crystallization and melting behavior of $\mathrm{PP} /$ nanoclay $/ \mathrm{CaCO}_{3}$ ternary nanocomposite. Journal of Applied Polymer Science, 124, 1225-1233 (2012). DOI: $10.1002 / a p p .35134$

[54] Deshmukh G. S., Peshwe D. R., Pathak S. U., Ekhe J. D.: Nonisothermal crystallization kinetics and melting behavior of poly(butylene terephthalate) and calcium carbonate nanocomposites. Thermochimica Acta, 606, 66-76 (2015). DOI: $10.1016 /$ j.tca.2015.03.008

[55] Thomason J. L.: The influence of fibre length and concentration on the properties of glass fibre reinforced polypropylene. 6 . The properties of injection moulded long fibre PP at high fibre content. Composites Part A: Applied Science and Manufacturing, 36, 995-1003 (2005).

DOI: 10.1016/j.compositesa.2004.11.004

[56] Thomason J. L.: Structure-property relationships in glass-reinforced polyamide, Part 1: The effects of fiber content. Polymer Composites, 27, 552-562 (2006). DOI: $10.1002 / p c .20226$

[57] Miri V., Elkoun S., Peurton F., Vanmansart C., Lefebvre J-M., Krawczak P., Seguela R.: Crystallization kinetics and crystal structure of nylon6-clay nanocomposites: Combined effects of thermomechanical history, clay content, and cooling conditions. Macromolecules, 41, 9234-9244 (2008).

DOI: $10.1021 / \mathrm{ma} 801804 \mathrm{y}$

[58] Yalcin B., Valladares D., Cakmak M.: Amplification effect of platelet type nanoparticles on the orientation behavior of injection molded nylon 6 composites. Polymer, 44, 6913-6925 (2003).

DOI: $10.1016 /$ j.polymer.2003.07.010

[59] Thomason J. L., van Rooyen A. A.: Transcrystallized interphase in thermoplastic composites. Part II Influence of interfacial stress, cooling rate, fibre properties and polymer molecular weight. Journal of Materials Science, 27, 897-907 (1992). DOI: $10.1007 / \mathrm{BF} 01197639$ 